\title{
LAG EFFECTS IN MORPHODYNAMIC MODELLING OF ENGINEERING IMPACTS
}

\author{
Michiel A. F. Knaapen ${ }^{1}$ and David M. Kelly ${ }^{1}$
}

\begin{abstract}
This paper details the extension of the sediment transport and morphology model SISYPHE to include a lag term within the bed exchange source term of the, depth-averaged, continuity of sediment concentration equation. This lag term represents the time it takes for a sediment concentration profile to adapt to spatial or temporal changes in the flow. The inclusion of a lag term means that the settling velocity is no longer the only scaling factor for the exchange of sediment between the water and the bed. The modified sediment transport and morphodynamics model is tested against field data from the Thames estuary (UK) and on the morphodynamic development of a dredged trench in flume experiments. It is illustrated that the lag factor introduced is essential to model the sediment transport and morphodynamics, especially when considering engineered situations, where the bed is out of equilibrium with the flow conditions. Moreover, with this lag factor included, there is evidence that SISYPHE can be used for morphodynamic modeling of engineered situations.
\end{abstract}

Keywords: sediment transport modeling; morphodynamics modeling; hysteresis effects; model validation

\section{INTRODUCTION}

In many sediment transport and morphology models in 2 horizontal dimensions, such as TELEMAC SISYPHE, Delft3D and MIKE, the erosion deposition mechanism assumes equilibrium conditions. In these models, it is assumed that the sediment concentration profile in the vertical instantaneously adapts to any spatial or temporal variations in the flow. This means that the sediment exchange rate between the bed and the water column is governed by the difference between the amount of sediment in the water column and the equilibrium sediment concentration, scaled solely by the settling velocity of the sediment under consideration (Mei, 1969).

This assumption of an instantaneous response of the sediment concentration profile to sudden variations in the flow is invalid in many cases. When there are changes in the depth averaged flow, such as tidal conditions, flow deceleration over a dredged channel or flow accelerations through a constriction, the flow profile will also be disturbed and the related profile for the saturated sediment concentration will be disturbed. Due to inertia effects, it takes time for the flow profile and saturated sediment concentration profile to adjust to the new depth averaged velocity. This introduces a hysteresis effect in the sediment concentrations during a tidal cycle. For equal flow velocities, the observed sediment concentrations are higher in a decelerating flow than in an accelerating flow (for example: Whitehouse and Thorn ,1997; Oeurng et al, 2010; Humphries et al. 2012). This effect is important for a large range of sediments, but especially for fine grained sediments.

This difference between actual and equilibrium concentrations creates a lag effect: the actual exchange between the bed and the water column is lower than predicted using the assumption of equilibrium conditions. This also implies that the bed changes occur more slowly than is predicted assuming equilibrium conditions. The errors made using the assumption of equilibrium sediment concentrations are most apparent in the case of engineering problems, which often introduce rapid changes in the local flow velocities. Based on information from deposition rates and concentrations in a dredged channel Lean (1980) proposed an alternative for the bed boundary condition exchange for the sediment exchange of Mei (1969).

Based on this Miles (1981) derived a solution of the 1D suspended sediment concentration equation, taking inertia effect of the sediment into account, utilizing the bottom boundary conditions proposed by Lean (1980). This paper reports on the introduction of this lag effect in the sediment transport to SISYPHE in order to parameterize the effect of settling lag on suspended sediment concentration and the associated morphological evolution based on Miles (1981).

\section{INCLUDING HYSTERESIS IN SEDIMENT TRANSPORT EQUATIONS}

Most sediment transport models contain a suspended-load transport equation of the form:

\footnotetext{
${ }^{1}$ HR Wallingford, Howbery Park, Wallingford, OX10 8BA, United Kingdom
} 


$$
\begin{aligned}
\frac{\partial \bar{C}}{\partial t}+u_{\text {conv }} \frac{\partial \bar{C}}{\partial x}+v_{\text {conv }} \frac{\partial \bar{C}}{\partial y}=\cdots & \\
& \frac{1}{h}\left\{\frac{\partial}{\partial x}\left(h \varepsilon \frac{\partial \bar{C}}{\partial x}\right)+\frac{\partial}{\partial y}\left(h \varepsilon \frac{\partial \bar{C}}{\partial y}\right)+F\left(\bar{C}_{s}-\bar{C}\right)\right\},
\end{aligned}
$$

where $\bar{C}$ and $\bar{C}_{S}$ are the depth-averaged concentration and depth-averaged saturated concentration respectively, $h$ is water depth. The convection velocities $u_{\text {conv }}$ and $v_{\text {conv }}$ are obtained by multiplying the depth-averaged flow velocities through by a convection factor $\left(F_{\text {conv }}<1\right)$ determined by the product of the velocity profile used and the sediment concentration profile used, $\varepsilon$ is a dispersion coefficient and $F$ is a scaling factor that includes the fall velocity and a profile parameter relating depth averaged and reference level concentrations: $\beta_{s}=C \bar{C}^{-1}$.

According to the accepted theory of sediment suspension turbulence opposes gravity and ensures that the sediment is distributed vertically throughout the water column. The continuity of sediment concentration equation in one, vertical, dimension is:

$$
\frac{\partial C}{\partial t}=W_{s} \frac{\partial C}{\partial z}+\frac{\partial}{\partial z}\left(D_{z} \frac{\partial C}{\partial z}\right)
$$

where $W_{s}$ is fall velocity. The vertical diffusivity $D_{z}$, which is approximated from the horizontal parabolic eddy viscosity assuming a logarithmic velocity profile, which describes the time rate of change of sediment in the vertical, $z$, direction for uniform flow conditions (Mei,1969):

$$
D_{z}=1 / 6 \kappa u_{*} h,
$$

where $u_{*}$ is the friction velocity and $\kappa=0.4$ is von Karman's constant. Solutions to equation (2) can be found by employing suitable boundary conditions. The free surface boundary is trivially defined as, at the free surface, there must be zero flux of sediment. At the bed there are a number of options and various assumptions have been made to describe the exchange of sediment between the water and the bed. Mei (1969) assumes that the concentration at the bed responds instantaneously to changes in the flow; such an assumption is, however, unrealistic as it requires that the rate of exchange of sediment is infinite at some initial time. Lean (1980) argued that it is the sediment entrainment rate that responds most rapidly to changes in the flow leading to bottom boundary conditions that can be expressed mathematically as:

$$
\left(D_{z} \frac{\partial C}{\partial z}\right)_{z=0}=\left(D_{z} \frac{\partial C_{S}}{\partial z}\right)_{z=0} .
$$

where the saturated concentration $\mathrm{C}_{\mathrm{s}}$ is the concentration that is in equilibrium with the flow and fulfils:

$$
W_{s} \frac{\partial C}{\partial z}+\frac{\partial}{\partial z}\left(D_{z} \frac{\partial C}{\partial z}\right)=0
$$

Boundary condition (4) is a more generic condition than that suggested by Mei (1969) but does include the boundary condition of Mei.

Following the approach suggested by Mei (1969), Miles (1981) derived a similarity solution to equation (2) for the bottom boundary conditions given in equation (4). This solution provides an approximate explicit analytical solution for $C$. Using this solution Miles (1981) shows that the erosion deposition source term can be written as:

$W_{s}\left(C_{S}-C\right)_{z=0}=W_{s}\left(\left(1+2 \tau^{2}\right) \mathrm{E}(\tau)-2 \tau \pi^{-\frac{1}{2}} e^{-\tau^{2}}\right)\left(C_{S}-C_{0}\right)_{z=0}$

where $C_{0}$ is the initial near bed concentration and: 
$\tau=\left(W_{s} / 4 D_{z}\right)^{\frac{1}{2}} t^{\frac{1}{2}}$

is the non-dimensional time and $E(\tau)$ is the error function. This modified source term now incorporates a scaling factor that accounts for both the settling velocity and the lag time required for the saturation concentration profile to adjust to changes in the flow.

\section{SATURATED CONCENTRATION}

The choice of the formulation for the saturation concentration of the sediment is not important within the context of this paper. A saturated concentration is used based on the Soulsby-van Rijn formulation for suspended load (Soulsby, 1997). This allows the use of a transport formula that is well calibrated and has been shown to predict reliable sediment transport rates under equilibrium conditions (Soulsby, 1997). At the same time this approach allows the use of the concentration equation, improving the model when lag effects are important.

The (depth-averaged) sediment transport rate, $q_{s}$ of Soulsby- van Rijn is converted into a (depthaveraged) saturated concentration using:

$$
\bar{C}_{s}=q_{s}(h \bar{U})^{-1}
$$

This is then converted in a saturated concentration at the reference level using the concentration profile $F$ :

$C_{s}=\bar{C}_{s} W_{s}^{-1} F=q_{s} F\left(W_{s} h \bar{U}\right)^{-1}$ :

This approach allows the model to calculate the Soulsby-van Rijn transport formula, while treating the suspended transport rates through the concentration equation.

\section{TEST 1: OUTER THAMES ESTUARY}

During 1971 and 1972 HR Wallingford undertook a study of the potential infilling of an approach channel at Foulness in the outer Thames estuary, UK (Figure 1). Simultaneous sediment concentration and velocity profile data was collected in the deep water channels of the estuary. The data is characteristic of the transport of fine sand by strong tidal flows in deep water without any influence from wave stirring (average wind speed was 5 knots and the wave stirring was negligible at depths of 3$7 \mathrm{~m})$. Refer to Whitehouse and Thorn (1997) for an in-depth summary of the data.

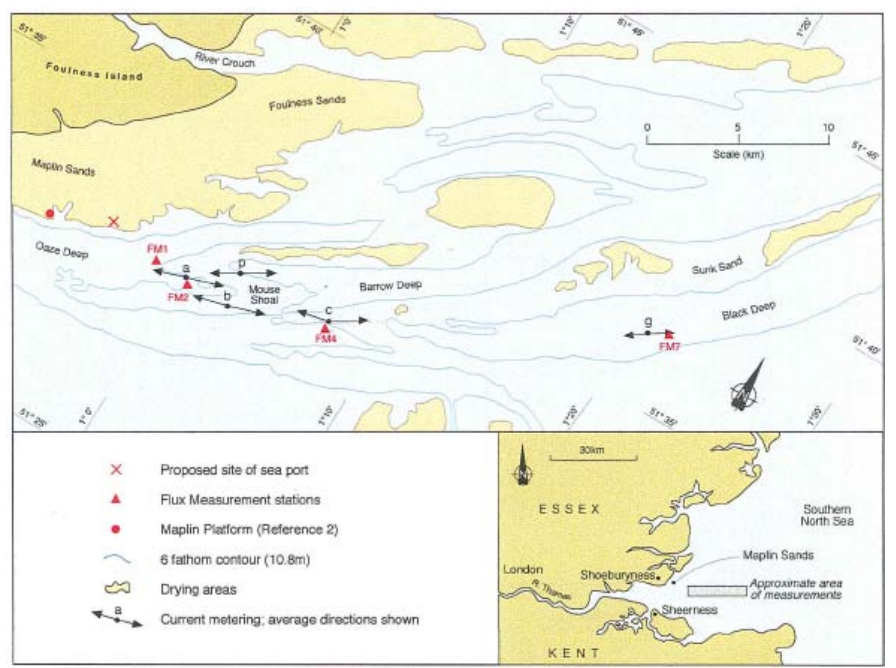

Figure 1. Map of the outer Thames estuary showing the location of the flux measurement stations

The modified version of SISYPHE was run employing a simple numerical flume with a horizontal bed. Currents and water depths observed at location FM1, where the tidal range is $5.2 \mathrm{~m}$; with the maximum flow velocity $1 \mathrm{~m} / \mathrm{s}$ during ebb and $1.1 \mathrm{~m} / \mathrm{s}$ during flood (refer to Whitehouse and Thorn, 
1997 for more details). These conditions were applied uniformly across the channel. Boundary conditions at either end of the flume were provided by forcing saturated sediment concentrations there. Thus, the effect of the non-uniform bottom topography on the flow, present at the data site, is not accounted for. The particle distribution of the sediment collected at FM1 consisted of silt and fine sand. The bed material was shown to consist of fine sand (median grain size $160 \mu \mathrm{m}$ ) with a long tail of fine material. The measured suspended material was finer (median grain size $100 \mu \mathrm{m}$ ). To cover both fine-sand and silt dynamics, a simulation employing a mixed sediment bed: $75 \mu \mathrm{m}$ (33\%), $125 \mu \mathrm{m}$ (33\%), $150 \mu \mathrm{m}$ (29\%) and $200 \mu \mathrm{m}$ (5\%) was run in order to best represent the measured bed composition simply.

Figure 2 shows the computed depth-averaged saturated and the computed actual concentrations for the fraction with $\mathrm{D}_{50}=150 \mu \mathrm{m}$, as computed in the mixed sediment case. The figure illustrates the lag introduced by modifying the entrainment-deposition source term; one can see that the actual lags behind the saturated concentration in both the entrainment and deposition phases of the tidal cycle. With smaller grain sizes, this lag becomes longer in the deposition phase, but slightly shorter in the erosion phase.

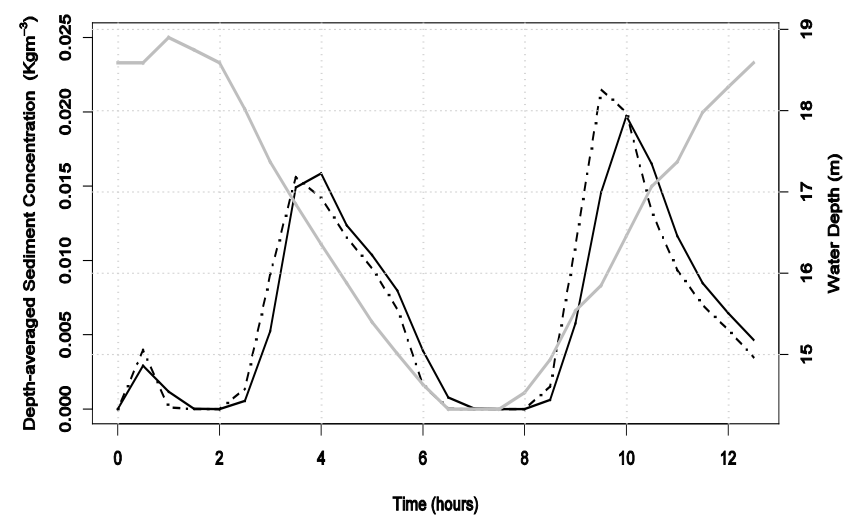

Figure 2. Computed saturated concentration (dashed black), computed actual concentration (solid black) for $D_{50}=75 \mu \mathrm{m}$, and water depth (solid grey). It shows the actual concentrations lagging behind the saturation values.

Figures 3 and 4 show a comparison between the predicted transport rates over time against the measured values when using a mixed sediment composition that is similar to the measured bed composition, with a $150 \mu \mathrm{m}$ median grain size. Both figures shows the hysteresis effect, with higher sediment concentrations in the decelerating flow than in the accelerating flow and the concentrations still increasing after the peak of the tidal velocities. The model reproduces the transport rates during the floods (Figure 3) quite well, but under-predicts the ebb tide transport rates (Figure 4).

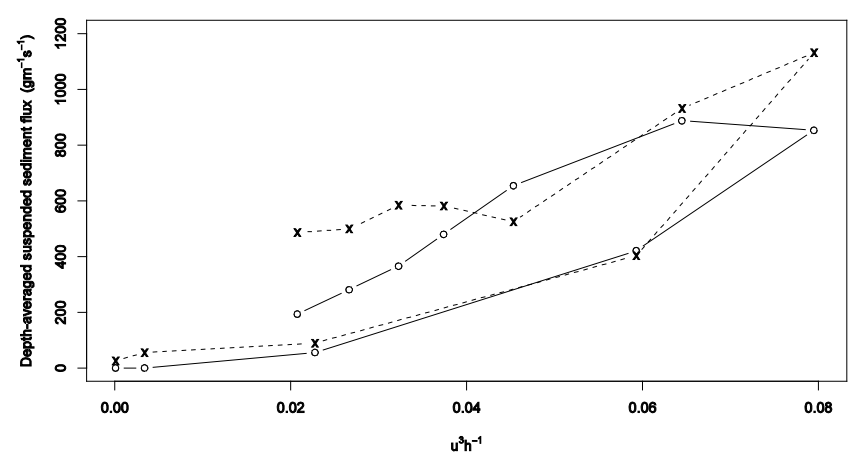

Figure 3. Measured (dashed) and computed (solid), with mixed sediments, depth-averaged sediment fluxes at half-hourly intervals for Foulness FM1 during flood phase 


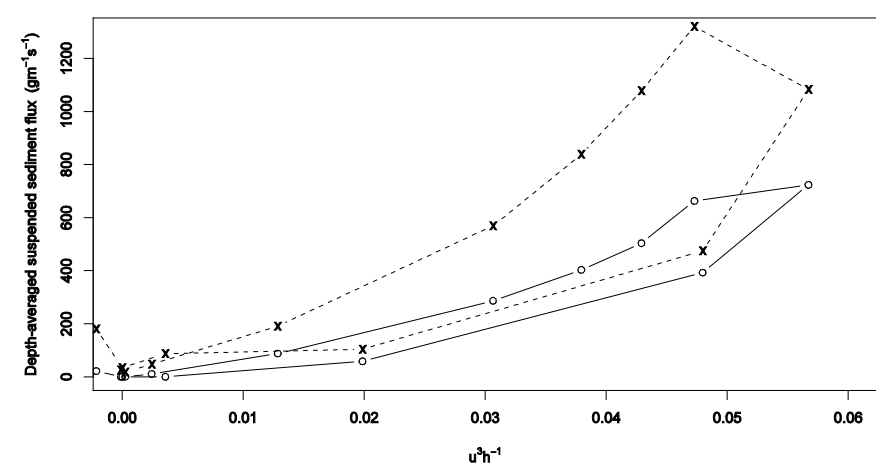

Figure 4. Measured (dashed) and computed (solid), with mixed sediments, depth-averaged sediment fluxes at half-hourly intervals for Foulness FM1 during ebb phase

To further investigate the difference in prediction error for the ebb and flood phases, we modeled the transport with separate fractions of $75 \mu \mathrm{m}, 100 \mu \mathrm{m}$, and $150 \mu \mathrm{m}$. It was found that the transport rates for the ebb stage are well reproduced using sediment with a $75 \mu \mathrm{m}$ diameter (Figure 5), but that these simulations overestimate the transport during the flood phase. In contrast, simulations using sediment with a $100 \mu \mathrm{m}$ diameter give accurate predictions of the transport during flood, but underpredict transport during the ebb. The simulations using a sediment with a $150 \mu \mathrm{m}$ diameter underpredict the transport rates in both the ebb and flood phase.

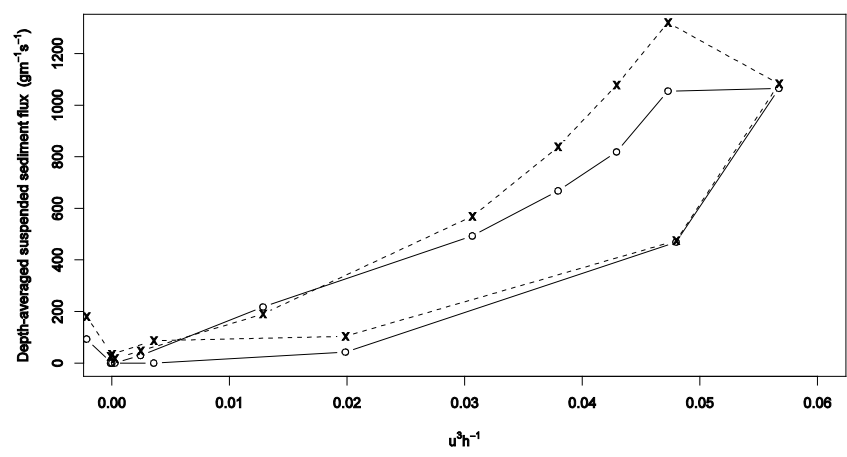

Figure 5. Measured (dashed) and computed (solid), assuming $75 \mu \mathrm{m}$ sediment, depth-averaged sediment fluxes at half-hourly intervals for Foulness FM1 during ebb phase

\section{TEST 2: TRENCH INFILL}

Flume experiments carried out at Delft Hydraulics [6] form the second test for the new version of SISYPHE. The experiments were performed in a small flume with a length of $17 \mathrm{~m}$, a width of $0.3 \mathrm{~m}$ and a depth of $0.5 \mathrm{~m}$. Sediment was used with $\mathrm{D}_{50}=0.1 \mathrm{~mm}$ and $\mathrm{D}_{90}=0.13 \mathrm{~mm}$. Sand was supplied at constant rate at upstream section of flume to maintain equilibrium conditions. The channel had side slopes of 1 in 10 and a depth of $0.125 \mathrm{~m}$.

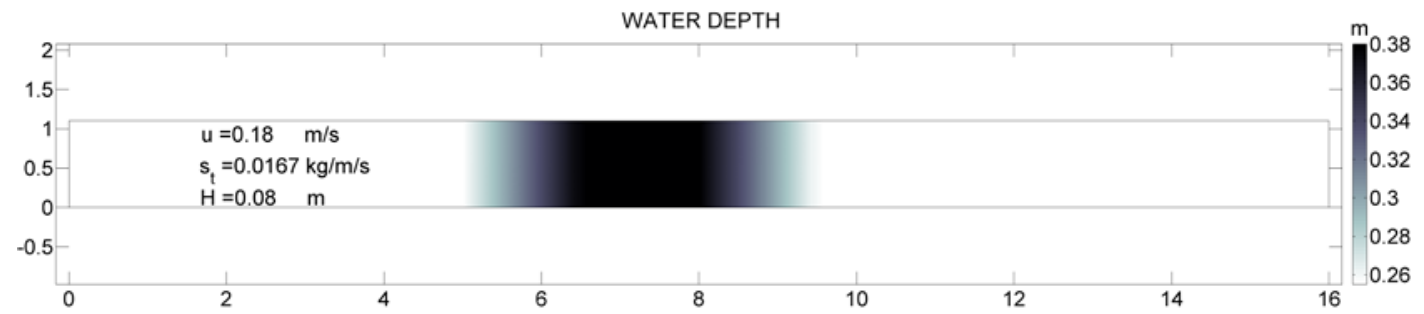

Figure 6. Layout of the flume, initial bathymetry (color scale) and the hydrodynamic conditions during the flume experiment. 
Regular waves with a period of $1.5 \mathrm{~s}$ and height of $0.08 \mathrm{~m}$ were generated and a steady current following the waves was imposed. The water depth was $0.255 \mathrm{~m}$ and the current velocity was $0.18 \mathrm{~m} / \mathrm{s}$. The mobile bed consisted of well sorted sediment with $0.1 \mathrm{~mm}$ median diameter $\left(\mathrm{D}_{90}=0.13 \mathrm{~mm}\right)$ and density $2650 \mathrm{~kg} / \mathrm{m} 3$. The mean fall velocity of the suspended sediment was $0.07 \mathrm{~m} / \mathrm{s}$.

To maintain equilibrium bed conditions away from the channel, $0.0167 \mathrm{~kg} / \mathrm{s} / \mathrm{m}$ sediment was fed into the flume at the inflow boundary.

Velocities (acoustic-Doppler) and suspended concentration (siphon system) profiles were measured at five stations near the trench at the initial stage of the experiment, when morphodynamic change was negligible.

Using Soulsby-van Rijn at these scales is impossible, as this formula is invalid for water depths smaller than $1 \mathrm{~m}$. This limitation is circumvented by scaling the experiment up to field dimensions, multiplying the domain lengths by 10 and the time 1 dy 0 . Assuming the morphology is bed -load dominated, the sediment grain size has not been altered (van Rijn et al, 2011). Assuming the morphology is suspended-load dominated, the sediment grain size is also multiplied by $\sqrt{ } 10$ (van Rijn et al, 2011). After the simulation, the time and spatial dimensions are rescaled back to the scales of the flume experiment.

The sediment transport and morphodynamics of the experiment were simulated using the existing option in SISYPHE with Soulsby- van Rijn as a total load predictor (referred to as 'total load' option), using the modified Soulsby-van Rijn method described in section III, (referred to as SISYPHE Mei) and the full modified Soulsby-van Rijn including lag (referred to as SISYHPHE Miles)

Figure 8 shows the results of the three options under the assumption that the morphodynamics are dominated by bed-load sediment transport. With the lag factor included, SISYPHE Miles predicts the location of the trench accurately and reproduces both the slopes correctly, even if the measured upstream slope has progressed slightly further than the modeled one. There are some minor errors, however, as the downstream bed level is eroding slightly (error $6.5 \mathrm{~mm}$ ) and the infill in the centre is slightly under-predicted (error $6.5 \mathrm{~mm}$; or $<10 \%$ ).

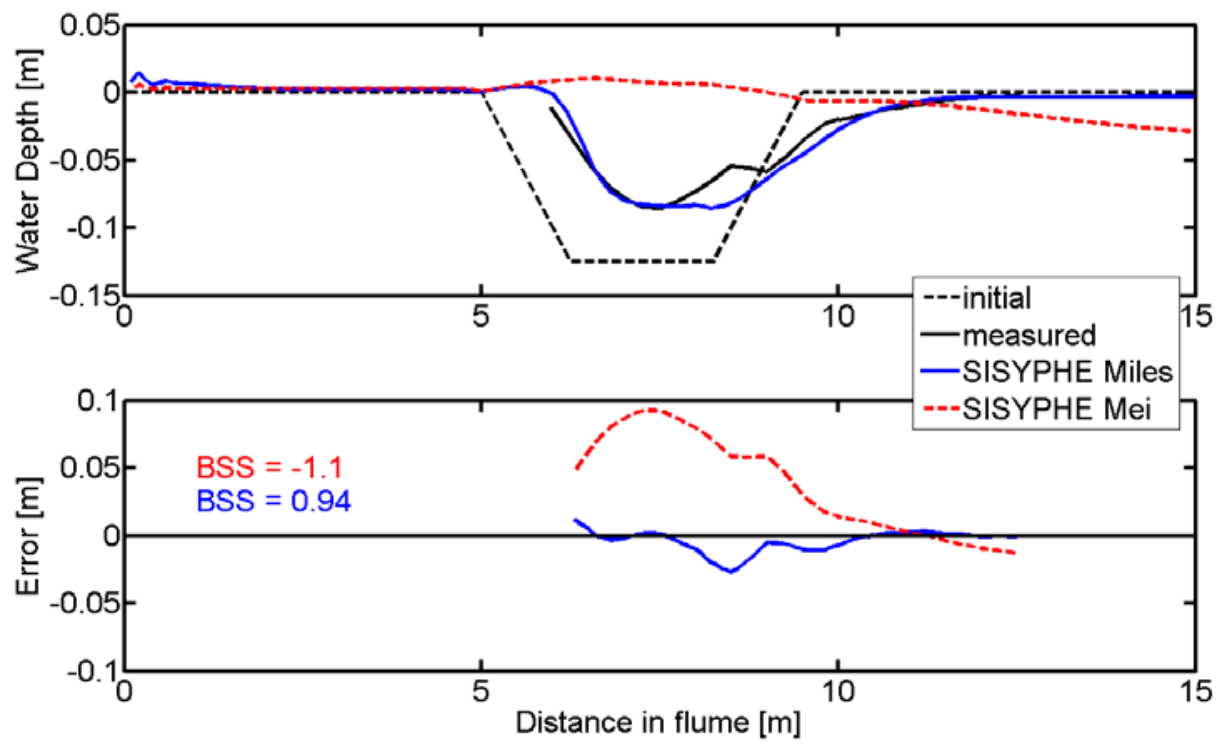

Figure 7. Trench profiles measured at the start of the experiment(dashed black) and after 10 hours (solid black) compared to model simulations using the different versions of Soulsby van Rijn's transport predictor existing SISYPHE (solid red), modified SISYPHE without lag effects (Mei, dashed red) and modified SISYPHE with lag effects SISYPHE (Miles, solid blue). The model grain size is $0.1 \mathrm{~mm}$. The BSS denotes the brier skill score, a measure to quantify model quality (Sutherland et al, 2004).

Both simulations without the lag factor contain considerable errors, even if the total load option predicts the change in depth of the trench quite well. The centre of the channel migrated $4.5 \mathrm{~m}$ (total 
load) too far. The upstream slope of the trench is too steep and the downstream slope to gentle in the total load option. Moreover, boundary issues this option in SISYPHE to deposit significant amounts of sediment upstream of the trench.

SISYPHE without lag effects over-predicts the infill of the channel and the centre of the channel migrates $5 \mathrm{~m}$ (SISYPHE Mei) too far.

To check that the assumption of bedload dominance is correct, the models have been run with the scaled grain sizes (e.g. $0.32 \mathrm{~mm}$ diameter instead of $0.1 \mathrm{~mm}$ ). Figure 9 then shows that all models underestimate the infill rate and slightly overestimate the downstream migration of the trench.

The simulation with the modified version of SISYPHE predicts slightly more infill than both simulations without lag effect. The simulations without lag effects are virtually identical, apart from some boundary effects.
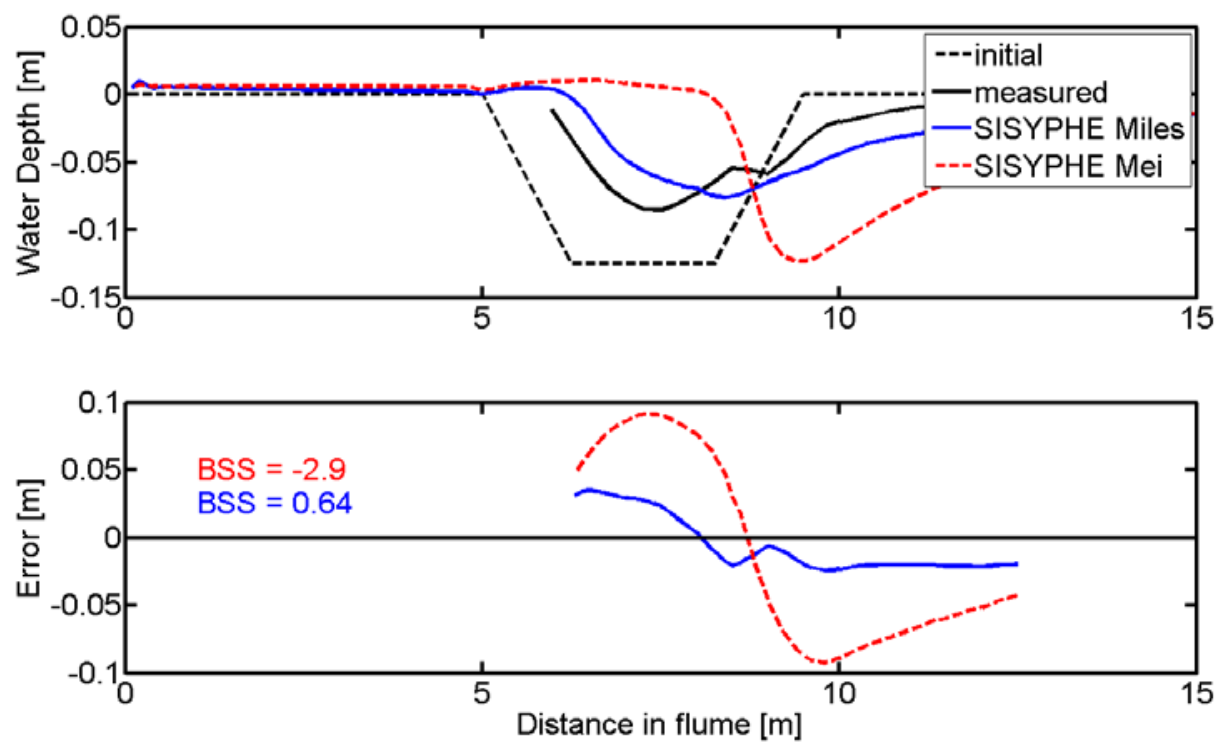

Figure 8. Trench profiles measured at the start of the experiment(dashed black) and after 10 hours (solid black) compared to model simulations using the different versions of Soulsby van Rijn's transport predictor existing SISYPHE (solid red), modified SISYPHE without lag effects (Mei, dashed red) and modified SISYPHE with lag effects SISYPHE (Miles, solid blue). The modeling grain size is $0.32 \mathrm{~mm}$. The model grain size is $0.1 \mathrm{~mm}$. The BSS denotes the brier skill score, a measure to quantify model quality (Sutherland et al, 2004).

\section{DISCUSSION AND CONCLUDING REMARKS}

An algorithm to model sediment transport based on the Soulsby-van Rijn transport predictor (Soulsby, 1997) has been added to SISYPHE. This algorithm converts the formula for the suspended load transport rate of Soulsby-van Rijn into a reference concentration that can then be transported using advection diffusion.

Furthermore, a lag factor for the erosion and deposition rate is developed for situations where the sediment concentrations are not in equilibrium with the flow conditions due to temporal and spatial variations in the flow. This lag factor is based on Miles' solution of the 1D suspended sediment concentration equation (Miles, 1981), taking inertia effect of the sediment into account, utilizing the bottom boundary conditions proposed by Lean (1980).

This new version of SISYPHE has been tested for three distinct test cases. The modified code has been applied to simulate the transport rates measured in the outer Thames estuary UK (Foulness). The transport rates were calculated using a mixed sediment bed with a grain distribution similar to the measured distribution. The simulated transport rates agreed well with observed transport rates during the flood tide, including the hysteresis effects; the concentration differences between accelerating and decelerating tides.

However, during the ebb tide, the transport rates were under-estimated in the simulations. Additional runs with single grain bed material showed a good agreement between the observed 
transport rates during ebb if the grain size was $75 \mu \mathrm{m}$. This is the observed grain size of the suspended sediment (Whitehouse and Thorn, 1997).

Based on these results, we conclude that the main differences between the predicted and measured concentrations for the mixed sediment simulation are caused by the simplification of the modeling domain. Where the simulation is using a straight flume with uniform sediment, in reality the Foulness measurement are taken in the Thames.

A possible explanation might be that the suspended transport during the ebb is dominated by the finer material from further up the estuary, but no confirmation for this explanation has been found in the experimental data.

The modified version of SISYPHE is also able to simulate the infill of a trench over time as measured in the flume by van Rijn (1986). Both the location of the trench and the infill rate were estimated accurately (the depth difference was less then $10 \%$ of the trench depth). To achieve this accuracy, the lag factor is essential as it enhances the infill rates and reduces the migration of the trench.

In the third test case, where a channel with a widening section in the middle is modeled, the lag effect creates a smooth transition of the sediment concentrations between the wide and the narrow sections.

In conclusion, it has been illustrated that the lag factor introduced into SISYPHE is essential to model both sediment transport and morphodynamics. Moreover, with this lag factor included, there is evidence that SISYPHE can be used for (short term) morphodynamic modeling of engineered situations, where the bed is out of equilibrium with the local flow conditions.

\section{REFERENCES}

Humphries, R. Venditti, J.G. Sklar, L.S. and Wooster, J.K. 2012. Experimental evidence for the effect of hydrographs on sediment pulse dynamics in gravel-bedded rivers. Water Resources Research, 48.

Lean, G.H. 1980.Estimation of maintenance dredging for navigation channels, Hydraulics Research Station Wallingford, Wallingford.

Mei, C.C. 1969. Non-uniform diffusion of suspended sediment. Proceedings ASCE Journal of the Hydraulic Division. ASCE, 581-584.

Miles. G.V. 1981. Sediment transport models for estuaries, Hydraulics Research Station Wallingford, Wallingford.

Oeurng, C. Sauvage, S. and Sanchez-Perez, J-M. 2010. Dynamics of suspended sediment transport and yield in a large agricultural catchment, southwest France, Earth Surface Processes and Landforms, 35 (11), 1289-1301.

Soulsby, R.L. 1997. Dynamics of Marine Sands, Thomas Telford. London.

Sutherland, J. Walstra, D.J.R. Chesher, T.J. van Rijn, L.C. and Southgate, H.N. 2004. Evaluation of coastal area modelling systems at an estuary mouth. Coastal Engineering, 51, 119-142.

Van Rijn, L.C. 1986. Sedimentation of dredged channels by currents and waves, Journal of Waterway, Port, Coastal and Ocean Engineering, ASCE, 112 (5).

Van Rijn, L.C. Tonnon, P.K. Sánchez-Arcilla, A. Cáceres, I. and Grüne, J. 2011. Scaling laws for beach and dune erosion processes. Coastal Engineering, 58 (7), 623-636.

Whitehouse, R.J.S. and Thorn, M.F.C. 1997. Sediment Transport Measurements at Foulness in the Outer Thames Estuary, HR Wallingford, TR33. 